\title{
Excision of atrial myxoma using robotic technology
}

\author{
Changqing Gao, MD, Ming Yang, MD, Gang Wang, MD, Jiali Wang, MD, Cangsong Xiao, MD, \\ Yang $\mathrm{Wu}, \mathrm{MD}$, and Jiachun Li, BS
}

Objective: This study is to discuss a surgical approach for ideal and safe resection of atrial myxoma using the da Vinci S Surgical System (Intuitive Surgical, Inc, Sunnyvale, Calif).

\begin{abstract}
Methods: Nineteen consecutive patients underwent resection of atrial myxomas with the da Vinci S Surgical System. Mean age of the patients was $46 \pm 16$ years. Mean tumor size was $45 \times 5.5 \mathrm{~cm}$. Fifteen tumors were in the left atrium, of which 11 tumors arose from the interatrial septum, 2 from the posterocaudal wall, 1 from the root of the anterior leaflet of the mitral valve, and 1 from the left atrial roof. In 13 patients, exploration was conducted through a left atriotomy anterior to the pulmonary veins and excision was achieved by dissecting a plane through the atrial muscle at the point of attachment. In the first 2 patients, exploration and excision were conducted through an oblique right atriotomy. Four tumors were in right atrium, all of which were resected from the beating heart. The da Vinci instrument arms were inserted through three 1-cm trocar incisions in the right side of the chest. Via 4 port incisions and a $1.5-\mathrm{cm}$ working port, all the procedures were completed with a $30^{\circ}$ angled endoscope facing upward with the da Vinci S robot.
\end{abstract}

Results: Resection was successful in all patients. There were no operative deaths, strokes, or other complications. All the patients were discharged. No recurrences of tumor or septal leakage were found in the complete 1- to 18-month follow-up.

Conclusions: The excision of atrial myxomas with the da Vinci S Surgical System is feasible, efficacious, and safe. Surgical results are excellent. (J Thorac Cardiovasc Surg 2010;139:1282-5)

Traditionally, left atrial myxomas have been resected by median sternotomy with cardiopulmonary bypass (CPB). Recent advances in robotic instrumentation have facilitated endoscopic intracardiac procedure. ${ }^{1-7}$ For example, the atrial retractor (Intuitive Surgical, Inc, Sunnyvale, Calif) is an excellent device for atrial exposure, and transthoracic aortic crossclamps developed by Chitwood, Elbeery, and Moran ${ }^{4}$ enabled central aortic occlusion without the use of an intra-aortic balloon. However, whether the da Vinci S Surgical System (Intuitive) could achieve good exposure and ideal resection of left or right atrial myxomas remained obscure.

Since January 2007, using the da Vinci S Surgical System, we ${ }^{8-11}$ have performed more than 200 robotic cardiac operations, in which robotic resection of left or right atrial myxomas has been performed on 19 consecutive patients. In the present article, we intend to address the related issues on the ideal resection of left or right atrial myxoma to eval-

\footnotetext{
From the Minimally Invasive and Robotic Cardiac Surgery Center, Department of Cardiovascular Surgery, PLA General Hospital, Beijing, China.

This study was funded by the PLA General Hospital and Capital Development Grants. Disclosures: None.

Received for publication June 14, 2009; revisions received Aug 1, 2009; accepted for publication Sept 6, 2009; available ahead of print Oct 26, 2009.

Address for reprints: Changqing Gao, MD, Minimally Invasive and Robotic Cardiac Surgery Center, Department of Cardiovascular Surgery, PLA General Hospital, 28 Fuxing Rd, Beijing 100853, China (E-mail: gaochq301@yahoo.com).

$0022-5223 / \$ 36.00$

Copyright (c) 2010 by The American Association for Thoracic Surgery doi:10.1016/j.jtcvs.2009.09.013
}

uate the safety and efficacy of the procedure using robotic technology.

\section{PATIENTS AND METHODS}

Between January 2007 and June 2009, 19 consecutive patients (13 female and 6 male) underwent resection of left or right atrial myxomas with the da Vinci S Surgical System with approval from the Institutional Review Board of PLA General Hospital and informed consent. Mean age of the patients was $46 \pm 16$ years (range, 23-58 years), and atrial myxoma was confirmed echocardiographically in all patients. Mean weight was $64 \pm 10.1 \mathrm{~kg}$ (range, $48-74 \mathrm{~kg})$. The mean tumor size was $45 \times 6.0 \pm 11.5 \mathrm{~cm}(23 \times 46$ to $43 \times 74 \mathrm{~cm})$. Attachment sites of tumors were as follows: 11 left atrial tumors arose from the interatrial septum, 2 from the posterocaudal wall, 1 from the root of anterior leaflet of the mitral valve, and 1 from the left atrial roof. Four myxomas were located in the right atrium. All patients underwent a history and physical examination followed by a chest radiograph and transthoracic echocardiogram.

After induction of general anesthesia, all patients were intubated for single-lung ventilation. A transesophageal echocardiography (TEE) probe and arterial pressure monitoring line were inserted. Both a central venous catheter and a $15 \mathrm{~F}$ venous drainage cannula were placed percutaneously into the right internal jugular vein. External defibrillator patches were placed to subtend the maximum cardiac mass. Each patient was positioned with the right side of the chest elevated approximately $30^{\circ}$ and with the right arm tucked at the side. Femoral arterial ( $18 \mathrm{~F}$ or $20 \mathrm{~F})$ and venous cannulation $(21 \mathrm{~F}$ or $23 \mathrm{~F})$ (Medtronic, Inc, Minnneapolis, Minn) were performed through a 2-cm transverse right groin incision cutdown with the Seldinger guidewire method and TEE guidance. Bicaval venous drainage was instituted through the jugular and femoral/inferior vena cava cannulas.

The camera cannula was placed in the right, 2 to $3 \mathrm{~cm}$ lateral to the nipple in the fourth ICS. A $1.5-\mathrm{cm}$ incision was used as a working port in the same ICS for the patient-side surgeon (Figure 1). The da Vinci instrument arms were inserted through three $1-\mathrm{cm}$ trocar incisions in the right side of the chest. The right instrument arm generally was positioned 4- to 6-cm lateral 


\section{Abbreviations and Acronyms \\ $\mathrm{CPB}=$ cardiopulmonary bypass \\ ICS = intercostal space \\ TEE $=$ transesophageal echocardiography}

to the working port in the sixth ICS. The left instrument arm was positioned medial and cephalad to the right arm in the second or third ICS. The fourth arm trocar was placed in the midclavicular line in the fifth ICS (Figure 1). All resections of myxomas and the atrial closures were completed with the da Vinci $S$ robot.

$\mathrm{CPB}$ was initiated with kinetically assisted bicaval venous drainage. The aortic occlusion was performed with a Chitwood crossclamp (Scanlan International, Inc, Minneapolis, Minn) via the midaxillary line in the fourth ICS. Antegrade cold blood cardioplegic solution was administered directly through the anterior chest (second ICS) with a 14F angiocatheter, by which deairing was done and repeat doses could be given when necessary. TEE was used routinely to assist deairing. Carbon dioxide was insufflated continuously into the operative field for air displacement.

After the pericardium was opened, stay sutures were placed low on the pericardium on the right side to rotate the heart for optimal exposure of the left atrium. A left atriotomy was performed and exposure of left atrial myxomas was maximized with the atrial retractor (Intuitive; Figure 2). In 13 patients with left atrial myxomas, exploration was conducted through a left atriotomy anterior to the pulmonary veins. Total excision was achieved by dissecting a plane through the atrial muscle at the point of attachment (Figures 2 and 3). In the first 2 patients with left atrial tumors attached to the interatrial septum, exploration was through an oblique right atriotomy. The point of attachment of the tumor was identified by the presence of abnormal vascularity at the superior pole of the fossa ovalis. Incision was made in the septum medial to the fossa ovalis, and when the left atrium was entered, the incision was extended $360^{\circ}$ around the tumor attachment. Very small margins of the normal septal tissue were maintained, with almost no direct instrument contact with the tumor when it was villous (Figure 4). Four right atrial myxoms were completely resected from the beating heart with the superior and inferior venae cavae snared. All tumors were grasped by the tissue margins and deposited into an Endopouch Retriever (Ethicon Endo-Surgery, Cincinnati, Ohio) and extracted via the working port. The chamber was carefully inspected with the endoscope. Atrial septal defects were repaired with autologous pericardial patches with 4-0 polytetrafluoroethylene (Gore-Tex suture; W. L. Gore \& Associates, Inc, Flagstaff, Ariz) running suture in 2 patients via a right atriotomy and closed directly with 4-0 polytetrafluoroethylene running suture in 4 patients via a left atriotomy. For posterior myxomas, the subendocardial defects were also directly closed with 4-0 polytetrafluoroethylene running suture without pericardial patches, and the septa of the remaining cases were intact. The atriotomy was closed with 4-0 polytetrafluoroethylene running suture. After crossclamp release and meticulous intracardiac deairing by angiocatheter of antegrade cold blood cardioplegic solution, the patient was weaned from CPB. After removal of the cardioplegia angioscope, the cardioplegia site was closed with extracorporeal knot tying through the working port, and then chest tubes were inserted. Integrity of the septal closure was confirmed by TEE.

Data are shown as mean \pm standard error of the mean.

\section{RESULTS}

All patients had successful resection of left atrial myxomas with the da Vinci S Surgical System and were operated on by the same console surgeon and patient-side surgeon. The mean CPB and aortic crossclamp times were $98 \pm$ 20.5 and $45 \pm 11.9$ minutes, respectively. Total length of in-

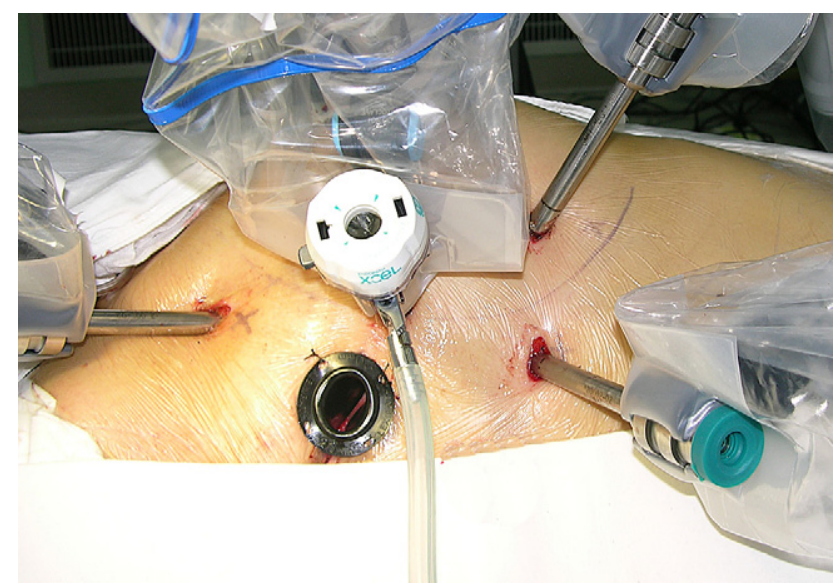

FIGURE 1. Setup of the da Vinci S Surgical System.

tensive care unit stay for patients was 0.5 to 1.5 days. The length of hospital stay for all patients was 5 to 7 days. The postrepair intraoperative and follow-up TEE showed removal of all tumors and no residual interatrial shunt. Pathologic examination revealed polypoid myxomas in 7 patients and villous myxomas in 12 patients.

There were no operative deaths, strokes, or other complications. All procedures that were started with the da Vinci Surgical System were completed with robotic assistance. All the patients were discharged, and cosmetic results were excellent in all cases (Figure 5). Patient follow-up was performed to obtain clinical and echocardiographic status. No recurrences of the tumor or septal leakage were found. The clinical results were excellent. The follow-up was 1 to 18 months and was $100 \%$ complete.

\section{DISCUSSION}

Minimally invasive approaches are being applied with increasing frequency in all areas of cardiac surgery, and cardiac tumors are no exception. Experience is confined to benign tumors and is quite limited. Approaches have included right parasteral or partial sternotomy exposure with standard cardioplegic techniques, ${ }^{12}$ right submammary incision with femoral-femoral bypass and nonclamped ventricular fibrillation, ${ }^{13}$ and right submammary port-access method with antegrade cardioplegia and ascending aortic balloon occlusion. ${ }^{14}$

Over the past few years, computerized surgical robotic systems have been developed very rapidly. The da Vinci surgical robot has assisted the surgeon's work using telemanipulation through a master-controller activation principle with a 3-dimensional intracardiac camera. Chitwood ${ }^{15}$ showed that endoscopic mitral valve surgery could be performed safely and with "gold standard" results. Surgical telemanipulation seems an ideal method for operating accurately through small incisions and in restricted spaces. In fact, robotic technology can provide many potential benefits 


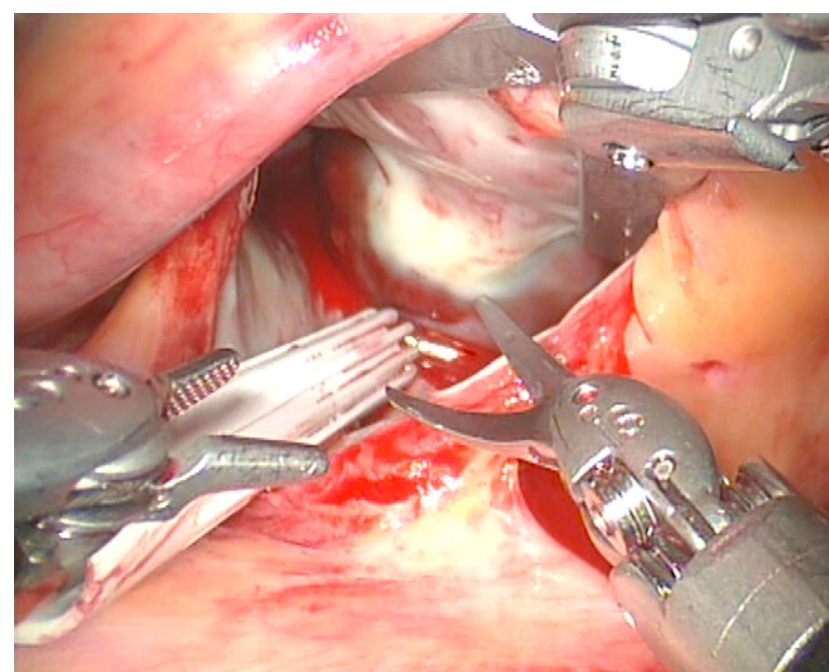

FIGURE 2. Exposure of left atrial myxomas with the atrial retractor.

to cardiac surgeons and patients. ${ }^{3-5}$ Cutaneous incisions can be smaller because of improved optics and instrumentation. Our working port was only $1.5 \mathrm{~cm}^{9}$ (Figure 1). Wristlike articulations transfer the dexterous actions of instrument tips to the plane of intracardiac procedures. With the addition of tremor filtration, there is improved precision in tight intracardiac spaces. Moreover, ambidexterity can become a reality for all surgeons.

In 2005, Murphy and associates ${ }^{16}$ reported the initial successful experience with left atrial myxoma excision with the da Vinci Surgical System. We have not found other reports about approaches for good exposure and ideal resection of left or right atrial myxomas with the da Vinci S Surgical System.

The surgical principles of myxoma excision include exposure of the attachment point of the tumor, allowing excision

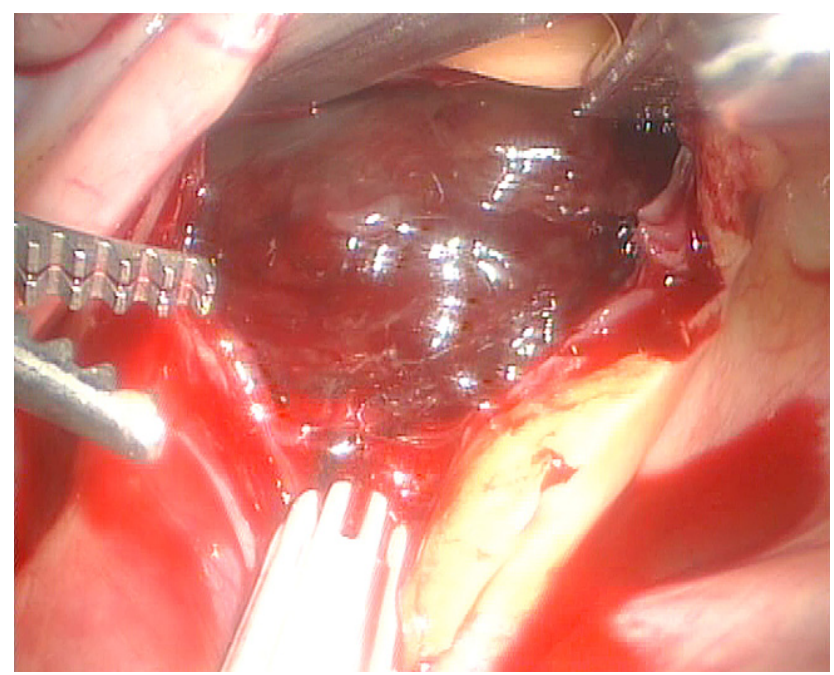

FIGURE 4. Almost no direct instrument contact with the tumor when it was villous.

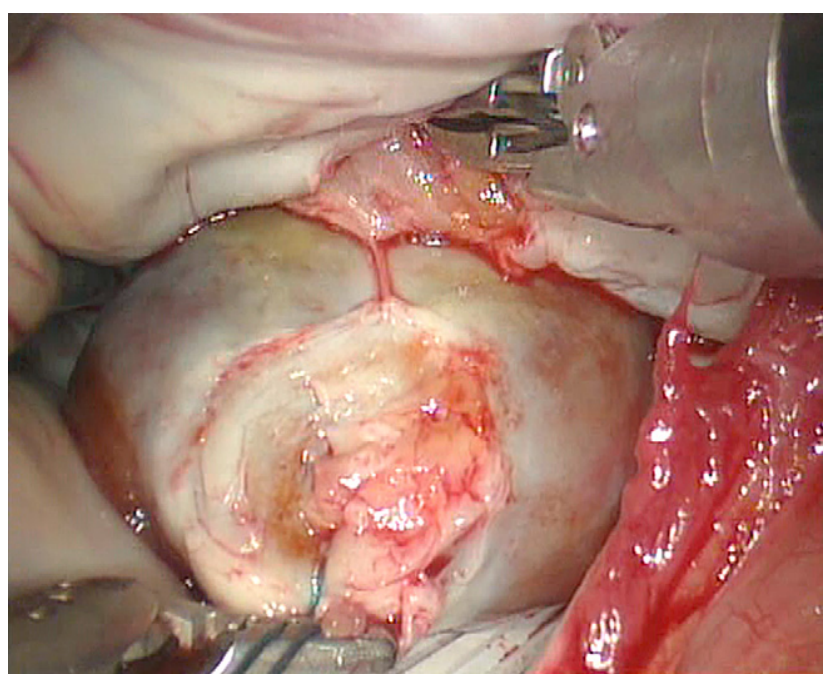

FIGURE 3. Total excision by dissecting a plane through the atrial muscle at the point of attachment.

of adequate tissue margins, removal of the tumor without fragmentation, reconstruction of atrial wall defects, and the ability to inspect the cardiac chambers for other tumors. ${ }^{17}$ We believed that exposure of left atrial myxomas was maximized by using several principles from mitral valve repair surgery with atrial retractors (Figure 2). We desired the right side of the heart to rotate up and the left side of the heart to rotate down. Therefore, stay sutures were placed low on the pericardium on the right side. This rotated the heart for optimal exposure of the left atrium. For left atrial tumors, the superior vena cava was extensively mobilized as was the inferior vena cava-right atrial junction, allowing increased mobility and exposing the left atrial cavity. Left atrial myxomas could be approached by an incision through

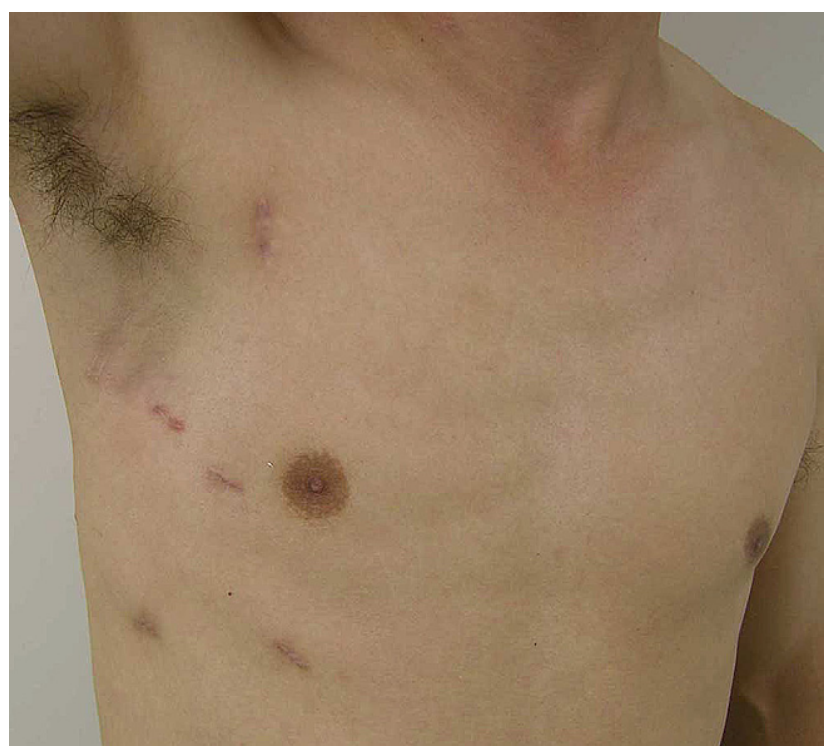

FIGURE 5. Cosmetic results were excellent. 
the anterior wall of the left atrium anterior to the right pulmonary veins. This incision could be extended behind both cavae for greater exposure. Right atrial myxomas could be resected directly through the right atrial incision from the beating heart without an aortic crossclamp.

The atrial retractor (Intuitive) is an excellent device for atrial exposure by the fourth arm (Figure 2). We believe that this device offers superior identification of the tumor attachment points to those that have been achieved in patients in whom the surgical approach has been via median sternotomy. Furthermore, left atrial myxomas can be approached more easily by the left atrial approach than the right; thus the stalk can be easily found and total excision can be achieved by dissecting a plane through the atrial muscle at the point of attachment with $10 \times$ magnification (Figure 3 ). Eleven of our 15 patients with left atrial myxoma were operated on through the left atrial approach.

Regardless of the surgical approach, the ideal resection encompasses the tumor and a portion of the cardiac wall or interatrial septum to which it is attached. Whether excision of full-thickness wall is necessary or excision of only an endocardial attachment is sufficient to prevent recurrence is controversial. ${ }^{18}$ Our policy was to resect full thickness whenever possible. When the stalk of myxoma originated in the septum, we tried to resect the stalk together with full septum, and the septum was then repaired. Actis Dato, ${ }^{19}$ McCarthy, ${ }^{20}$ and their associates reported that only partial thickness resection of the area of tumor attachment was performed when anatomically necessary without a noted increase in recurrence rate. In our study, we found that some stalks of myxoma were loosely attached to the endocardium, which could be easily resected robotically because of the $10 \times$ magnification. When the base/stalk of the myxomas was not completely resected when anatomically necessary, we cauterized the base of the myxomas to prevent recurrence.

Chitwood's aortic clamp technique ${ }^{4}$ is safe, simple, and economical compared with the remote access perfusion cannula with endoaortic balloon. In our group, aortic occlusion was completed with the Chitwood crossclamp via the fourth ICS in the midaxillary line. Cardioplegic solution administered antegradely directly through the anterior chest wall was feasible and safe. ${ }^{10}$ Therefore, the working port could become smaller. In our series, the robotic system performed safely and efficiently, with no operative deaths or conversions resulting from a system malfunction. Only 2 patients had temporary atrial fibrillation. Mean length of hospital stay was shorter than that with conventional surgical repair. These patients benefited from minimal trauma, early discharge, and excellent cosmesis.

Limitations include longer follow-up to determine whether the tumor recurs or not with the technique of partial thickness resection of the area of tumor attachment and whether the intracardiac or intramediasdinal tumor spills or not by removing the tumor in total with the endopouch and a no-touch technique.

With limited cases, we conclude that the left atrial approach allows satisfactory exposure and ideal excision of left atrial myxomas and that right atrial myxomas can be completely resected with the heart beating. Excision of atrial myxomas with the da Vinci S Surgical System is feasible, efficacious, and safe. Surgical results are excellent.

\section{References}

1. Argenziano M, Oz MC, Derose JJ, Ashton RC Jr, Beck J, Wang F, et al. Totally endoscopic atrial septal defect repair with robotic assistance. Heart Surg Forum 2002;5:294-300.

2. Casselman FP, Slyke SV, Dom H, Lambrechts DL, Vermeulen Y, Vanermen H. Endoscopic mitral valve repair: feasible, reproductive, and durable. J Thorac Cardiovasc Surg. 2003;125:273-82.

3. Chitwood WR Jr, Elbeery JR, Chapman WH, Moran JM, Lust RL, Wooden WA, et al. Video-assisted minimally invasive mitral valve surgery: the "micro-mitral", operation. J Thorac Cardiovasc Surg. 1997;113:413-4.

4. Chitwood WR, Elbeery JR, Moran JM. Minimally invasive mitral valve repair: using a mini-thoracotomy and transthoracic aortic occlusion. Ann Thorac Surg. 1997;62:1477-9.

5. Murphy DA, Miller JS, Langford DA, Snyder AB. Endoscopic robotic mitral valve surgery. I Thorac Cardiovasc Surg. 2006;132:776-81.

6. Nifong LW, Chitwood WR, Pappas PS, Smith CR, Argenziano M, Starnes A, et al. Robotic mitral valve surgery: a United States multicenter trial. J Thorac Cardiovasc Surg. 2005;129:1395-404.

7. Torracca L, Ismeno G, Alfieri O. Totally endoscopic computer-enhanced atrial septal defect closure in six patients. Ann Thorac Surg. 2001;72:1354-7.

8. Gao C, Yang M, Wang G, Wang JL, Li LX, Zhao Y, et al. Totally robotic internal mammary artery harvest and beating heart coronary artery bypass. Chin J Surg. 2007;45:1414-6.

9. Gao C, Yang M, Wang G, Wang JL, Li LX, Zhao Y, et al. Robotic atrial septal defect repair: preliminary experience with da Vinci S system. Chin J Thorac Cardiovasc Surg. 2007;23:298-300.

10. Gao C, Yang M, Wang G, Wang J. Totally robotic resection of myxoma and atrial septal defect repair. Interact Cardiovasc Thorac Surg. 2008;7:947-50.

11. Gao C, Yang M, Wu Y, Wang G, Xiao CS, Liu HB, et al. Hybrid coronary revascularization by endoscopic robotic coronary artery bypass grafting on beating heart and stent placement. Ann Thorac Surg. 2009;87:737-41.

12. Ravikumar E, Pawar N, Gnanamuthu R, Sundar P, Cherian M, Thomas S. Minimal access approach for surgical management of cardiac tumors. Ann Thorac Surg. 2000;70:1077-9.

13. Ko PJ, Chang CH, Lin PJ, Chu JJ, Tsai FC, Hsueh C, et al. Video-assisted minima access in excision of left atrial myxoma. Ann Thorac Surg. 1998;66:1301-5.

14. Gulbins H, Reichenspurner H, Wintersperger BJ. Minimally invasive extirpation of a left-ventricular myxoma. Thorac Cardiovasc Surg. 1999;47:129-30.

15. Chitwood WR. Current status of endoscopic and robotic mitral valve surgery. Ann Thorac Surg. 2005;79:s2248-53.

16. Murphy DA, Miller JS, Langford DA, Snyder AB. Robot-assisted endoscopic excision of left atrial myxomas. J Thorac Cardiovasc Surg. 2005;130:596-7.

17. Schroeyers P, Vermeulen Y, Wellens F, De Geest R, Degrieck I, Van Praet F, et al Video-assisted port-access surgery for radical myxoma resection. Acta Chir Belg. 2002;102:131-3.

18. Reardon MJ, Smythe WR. Cardiac neoplasms. In: Cohn LH, Edmunds LH Jr. eds. Cardiac surgery in the adult. 2nd ed. New York: McGraw-Hill; 2003:1381-2.

19. Actis Dato GM, de Benedictus M, Actis Dato A Jr, Ricci A, Sommarival L, De Paulis R. Long-term follow-up of cardiac myxoma (7-31 years). J Cardiovasc Surg (Torino). 1993;34:41-3.

20. McCarthy PM, Piehler JM, Schaff HV, Pluth JR, Orszulak TA, Vidaillet HJ Jr, et al. The significance of multiple, recurrent, and "complex" cardiac myxomas. J Thorac Cardiovasc Surg. 1986;91:389-96. 